6. Gardner RJ, Mackay DJ, Mungall AJ et al. (2000) An imprinted locus associated with transient neonatal diabetes mellitus. Hum Mol Genet 9: 589-596

7. Soliman AT, elZalabany MM, Bappal B, alSalmi I, de Silva V, Asfour M (1999) Permanent neonatal diabetes mellitus: epidemiology, mode of presentation, pathogenesis and growth. Indian J Pediatr 66: 363-373

8. Stoffers DA, Zinkin NT, Stanojevic V, Clarke WL, Habener JF (1997) Pancreatic agenesis attributable to single nucleotide deletion in the human IPF1 gene coding sequence. Nat Genet 15: 106-110

\section{No evidence of rapid onset (Japanese) Type I diabetes in Caucasian patients}

Dear Sir,

Type I (insulin-dependent) diabetes mellitus has been classified as an autoimmune (Type 1A) or idiopathic disease (Type 1B) [1]. The idiopathic group is poorly defined other than by its lack of islet cell antibodies including antibodies to glutamic acid decarboxylase (GAD). In a recent study of 56 consecutive Japanese patients with Type I diabetes, 20 did not have GAD antibodies. Of these 20 patients, 11 had glycated haemoglobin $\left(\mathrm{HbA}_{1 \mathrm{c}}\right)$ values (an index of preceding blood glucose values) less than $8.5 \%$, that is close to the upper limit of normal of $5.8 \%$. These 11 patients, compared with the other GAD positive and GAD negative patients, had a shorter duration of hyperglycaemic symptoms (mean 4 days), higher plasma glucose (mean $42.9 \mathrm{mmol} / \mathrm{l})$, lower urinary $\mathrm{C}$ peptide $(3.2 \mu \mathrm{g} /$ day $)$ and higher serum amylase (4.2 times upper limit of normal) [2]. The authors concluded that these Japanese patients with idiopathic Type I diabetes had a non-autoimmune, fulminant disorder characterised by an abrupt onset and high serum pancreatic enzyme concentrations. Because there are no similar analyses of Type I diabetic patients of Caucasian origin, we undertook an analysis of a consecutive series of Italian patients from a single region [3] who had been newly diagnosed with Type I diabetes. We studied 82 patients aged 5 to 35 years (mean age 19 years \pm 8 SD), diagnosed according to the recent classification of the American Diabetes Association [1] with sufficient serum available to measure autoantibodies and pancreatic amylase. Of the 82 patients, 59 had GAD antibodies and 23 did not. The characteristics of each group are shown in Table 1 . Contrary to the patients described in Japan [2], GAD positive patients at diagnosis had significantly lower $\mathrm{HbA}_{1 \mathrm{c}}$ and were older than GAD negative patients. Of the nine patients with $\mathrm{HbA}_{1 \mathrm{c}}$ less than $7.5 \%$ (which is close to the normal range and suggests a relatively rapid onset of diabetes) only one was GAD negative. They differed from those 59 with higher $\mathrm{HbA}_{1 \mathrm{c}}$ values in that they had a lower blood glucose concentration at diagnosis $(p<0.04)$ and required less insulin $(p<0.007)$. Of note, serum amylase concentrations did

Corresponding author: Prof. P. Pozzilli, Unit for Prevention of Diabetes \& Metabolic Diseases, University Campus Biomedico, Via Longoni 83, 00155 Rome, Italy
Table 1. Characteristics of 82 patients with recent onset Type I diabetes, according to the presence or absence of GAD antibodies

\begin{tabular}{lcll}
\hline & $\begin{array}{l}\text { GAD }+ \text { ve } \\
n=59\end{array}$ & $\begin{array}{l}\text { GAD }- \text { ve } \\
n=23\end{array}$ & $p$ value \\
\hline HbA $_{1 \mathrm{c}}(\% \pm \mathrm{SD})$ & $9.4 \pm 2.1$ & $10.8 \pm 2.3$ & $<0.01$ \\
Age $($ years $\pm \mathrm{SD})$ & $20.1 \pm 8.1$ & $15.8 \pm 7$ & $<0.02$ \\
Blood glucose $(\mathrm{mg} \pm \mathrm{SD})$ & $349 \pm 147$ & $408 \pm 181$ & $\mathrm{NS}$ \\
Symptoms $($ days $\pm \mathrm{SD})$ & $32.5 \pm 31.6$ & $37.9 \pm 25.2$ & $\mathrm{NS}$ \\
Insulin $(\mathrm{iU} / \mathrm{kg}) \pm \mathrm{SD}$ & $0.51 \pm 0.32$ & $0.64 \pm 0.33$ & $\mathrm{NS}$ \\
$\mathrm{C}$ Peptide $(\mathrm{ng} / \mathrm{ml}) \pm \mathrm{SD}$ & $0.96 \pm 0.56$ & $0.95 \pm 0.73$ & $\mathrm{NS}$ \\
Amylase $(\mathrm{unit} / \mathrm{l}) \pm \mathrm{SD}$ & $47.4 \pm 21.0$ & $49.9 \pm 18.6$ & $\mathrm{NS}$ \\
\hline
\end{tabular}

not differ between patients with or without GAD antibodies (Table 1) or $\mathrm{HbA}_{1 \mathrm{c}}$ values more or less than $7.5 \%$. Only one patient had an increased amylase concentration and that patient was GAD antibody positive with an $\mathrm{HbA}_{1 \mathrm{c}}$ of $12.1 \%$. We observed that the age of our patients was considerably less than that of the Japanese subgroup of GAD negative patients with increased serum amylase concentrations.

We were unable to identify a group of Type I diabetic patients of Caucasian origin at diagnosis with non-autoimmune fulminant disease associated with an increased amylase concentration. Therefore the new subtype of Type I diabetes mellitus reported in Japan [2] is specific to that population.

Yours faithfully,

P. Pozzilli, N. Visalli, D. Leslie and the IMDIAB Group

\section{References}

1. Report of the Expert Committee on the Diagnosis and Classification of Diabetes Mellitus (1997) Diabetes Care 20: 1183-1197

2. Imagawa A, Hanafusa T, Miyagawa JI, Matsuzawa $Y$ (2000) A novel subtype of Type I diabetes mellitus characterised by a rapid onset and an absence of diabetes-related antibodies. N Engl J Med 342: 301-307

3. Sebastiani L, Visalli N, Adorisio E, Suppa M, Buzzetti R et al. (1996) A five year (1989-1993) prospective study of the incidence of insulin dependent diabetes in Rome and the Lazio Region in the age group 0-14 years. Diabetes Care 19: 70-73

\section{High fasting glucose and QTc duration in a large healthy cohort}

Dear Sir,

Marfella et al. [1] reported the effects of acute hyperglycaemia on QTc duration in healthy men. They found that QTc dura-

Corresponding author: J.D. Lefrandt, University Hospital of Groningen, Department of Internal Medicine, Hanzeplein 1, 9713 GZ, The Netherlands tion increased from a basal $413 \pm 26$ to $442 \pm 29 \mathrm{~ms}(p<0.05)$ at the end of a hyperglycaemic clamp. As stated by the authors, the relevance of these short-term changes to the high mortality rates of diabetic patients is speculative. We provide data that support their findings in a large healthy cohort.

We studied the association between QTc duration, fasting glucose and cardiovascular risk factors in a population-based study of 6543 subjects without evidence of clinical or electrocardiographic cardiac abnormalities. Subjects with diabetes mellitus, defined as a fasting plasma glucose concentration of $7.8 \mathrm{mmol} / \mathrm{l}$ or more or the use of oral hypoglycaemic agents or in- 
Table 1. Linear and logistic regression analysis associating high fasting glucose concentration and cardiovascular risk factors with QTc duration

\begin{tabular}{|c|c|c|c|c|c|c|c|c|c|c|}
\hline \multirow[b]{3}{*}{ Variable } & \multicolumn{6}{|c|}{ Linear models of QTc duration } & \multicolumn{4}{|c|}{ Logistic models of prolonged QTc ( > $440 \mathrm{~ms}$ ) } \\
\hline & \multicolumn{3}{|c|}{ Model $1^{\mathrm{a}}$} & \multicolumn{3}{|c|}{ Model $2^{b}$} & \multicolumn{2}{|l|}{ Model $1^{\mathrm{a}}$} & \multicolumn{2}{|l|}{ Model $2^{b}$} \\
\hline & $\beta$ & $\operatorname{SE}(\beta)$ & $p$ & $\beta$ & $\operatorname{SE}(\beta)$ & $p$ & $\begin{array}{l}\text { Odds Ratio } \\
(95 \% \mathrm{CI})\end{array}$ & $p$ & $\begin{array}{l}\text { Odds Ratio } \\
(95 \% \mathrm{CI})\end{array}$ & $p$ \\
\hline $\begin{array}{l}\text { Glucose } \\
\left(>5.1 \mathrm{mmol} / \mathrm{l}^{\mathrm{c}}\right)\end{array}$ & 2.70 & 0.64 & $<0.001$ & 1.44 & 0.73 & 0.048 & $1.34(1.15-1.56)$ & $<0.001$ & $1.29(1.08-1.53)$ & 0.005 \\
\hline $\begin{array}{l}\text { Systolic blood pressure } \\
\left(>139 \mathrm{mmHg}^{\mathrm{c}}\right)\end{array}$ & 6.72 & 0.68 & $<0.001$ & 4.05 & 0.91 & $<0.001$ & $1.87(1.59-2.19)$ & $<0.001$ & $1.61(1.30-2.00)$ & $<0.001$ \\
\hline $\begin{array}{l}\text { Cholesterol } \\
\left(>6.30 \mathrm{mmol} / \mathrm{l}^{\mathrm{c}}\right)\end{array}$ & 1.01 & 0.65 & NS & 1.00 & 0.73 & NS & $1.02(0.87-1.19)$ & NS & $1.03(0.86-1.22)$ & NS \\
\hline $\begin{array}{l}\text { Body mass index } \\
\left(>28 \mathrm{~kg} / \mathrm{m}^{2 \mathrm{c}}\right)\end{array}$ & 2.78 & 0.63 & $<0.001$ & 1.07 & 0.73 & NS & $1.19(1.03-1.38)$ & 0.02 & $1.04(0.88-1.25)$ & NS \\
\hline Smoking & -0.87 & 0.54 & NS & -0.67 & 0.61 & NS & $0.85(0.75-0.97)$ & 0.02 & $0.92(0.79-1.07)$ & NS \\
\hline
\end{tabular}

$\beta=$ regression coefficient

${ }^{a}$ Each variable entered separately, adjusted for age and sex

${ }^{\mathrm{b}}$ High fasting glucose concentration and cardiovascular risk factors entered simultaneously including age and sex

c 75 -centile value

sulin, had been excluded. Standard twelve-lead ECGs were recorded with Cardio Perfect equipment (Cardio Control, Rijswijk, the Netherlands), stored digitally and classified using the computer program MEANS (Modular ECG Analysis System) [2]. The MEANS program measures the overall QT interval for all twelve leads together on a representative beat, which results from selective averaging of dominant beats. To adjust for heart rate Bazett's formula $(\mathrm{QTc}=\mathrm{QT} / \sqrt{\mathrm{RR}})$ was used. Blood pressure was measured with an automatic Dinamap XL Model 9300 series (Johnson-Johnson Medical Inc., Tampa, Fla., USA) device. Corresponding to the highest quartile of plasma glucose, a high fasting glucose was defined as above $5.1 \mathrm{mmol} / \mathrm{l}$. Continuous variables entered in the analyses were divided into quartiles and the highest quartile was tested against the three lowest. Linear and logistic regression were used to associate high fasting glucose with QTc duration and prolonged QTc (>440 ms) simultaneously controlled for potential confounders. For both linear and logistic analyses we adjusted for two sets of possible confounders: age and sex (model 1) and age, sex, and conventional cardiovascular risk indicators (model 2 ).

The average age of this cohort was $47 \pm 12($ mean \pm SD) with a range of $28-75$ years; $49 \%$ of the subjects were men. The mean plasma glucose was $4.7 \pm 0.7 \mathrm{mmol} / \mathrm{l}$ and mean QTc $420 \pm 23$ ms. Of our cohort $18 \%(n=1189)$ had a QTc greater than $440 \mathrm{~ms}$. Linear regression showed that QTc duration was associated with a high fasting glucose concentration, systolic and diastolic blood pressure and body mass index, adjusted for sex and age. The multivariate model showed that the association between high fasting glucose and QTc duration was independent of traditional cardiovascular risk factors. Logistic regression analysis showed that a prolonged QTc was associated with high fasting glucose concentration, systolic and diastolic blood pressure, body mass index and smoking, adjusted for sex and age. In the multivariate model, the association between QTc prolongation and high fasting glucose concentration was independent of traditional cardiovascular risk factors.

Our results confirm in a population-based study the association of QTc duration and plasma glucose that was found by Marfella et al. during acute hyperglycaemia in a laboratory setting. Moreover, we report an independent association of high plasma glucose concentration and QTc prolongation. The QTc prolongation is a condition that predisposes for cardiac arrhythmias and is associated with a high mortality not only in a population with coronary artery disease but even in an apparently healthy population [3-4]. Furthermore, Marfella used an euglycaemic clamp at a glucose concentration of $15 \mathrm{mmol} / \mathrm{l}$. Yet, we found that a fasting glucose concentration higher than $5.1 \mathrm{mmol} / \mathrm{l}$ is already predictive for prolongation of QTc. This is in line with a previous observation that even in non-diabetic subjects the level of $\mathrm{HbA}_{1 \mathrm{C}}$ is predictive for the occurrence of heart disease [5]. In conclusion, we confirm in a large healthy cohort that a prolonged QTc duration is related to high fasting glucose concentration in addition to conventional cardiovascular risk factors. Our findings confirm the conclusion of Marfella et al. that in subjects with high fasting glucose concentration QTc prolongation contributes to the increased cardiovascular risk.

Yours sincerely,

J.D. Lefrandt, G.F.H. Diercks, A.J. van Boven, H.J.G.M. Crijns, W.H. van Gilst, R. O.B. Gans

\section{References}

1. Marfella R, Nappo F, De Angelis L, Siniscalchi M, Rossi F, Giugliano D (2000) The effect of acute hyperglycaemia on QTc duration in healthy man. Diabetologia 43: 571-575

2. Bemmel van HG, Kors JA (1990) Methodology of the modular ECG analysis system MEANS. Methods Inf Med 29: $346-353$

3. Schwartz PJ, Wolf S (1978) QT interval prolongation as predictor of sudden death in patients with myocardial infarction. Circulation 57: 1074-1077

4. Schouten EG, Dekker JM, Meppelink P, Kok FJ, Vandenbroucke JP, Pool J (1991) QT interval prolongation predicts cardiovascular mortality in an apparently healthy population. Circulation 84: 1516-1523

5. Singer DE, Nathan DM, Anderson KM, Wilson PW, Evans JC (1992) Association of HbA1 c with prevalent cardiovascular disease in the original cohort of the Framingham Heart Study. Diabetes 41: 202-208 